\title{
EL SIGNIFICADO DE LA CERAMICA SEPULCRAL ANTROPOMORFA DE LOS MOCHICAS
}

\author{
H. D. DisseLhoff
}

La tendencia en sí necesaria de lograr una cronología relativa de las antiguas culturas peruanas, tuvo la culpa de que - a favor de la busca de estratigráficos yacimientos arqueológicos dentro de los basurales, a favor del recuento de fragmentos y de la calculación del porcentaje de los mismos en la sucesión de especies y estilos cerámicos- se hayan descuidado un poco los planteamientos desde el punto de vista de la Historia de la Cultura y de la Einología. Creo que investigando conjuntos sepulcrales enteros, podríálegarse-amén de otros procedimientos- a mejores respuestas para tales planteamientos.

La interpretación de problemas conectados con la historia del espíritu humano quedó abandonada en parte a aquellos científicos que conocen los resultados de los hechos arqueológicos sólo por segunda mano (1). En un trabajo que acaba de publicarse, Georg Eckert trata de la creencia, que se hubiera mantenido viva entre varios pueblos de la era primitiva, acerca de una continuación de la vida somática de los muertos. Tal suposición de un "cadáver vivo", según él, fuera también responsable de las plásticas antropomorfas en oro que crearon los pueblos del valle Cauca de Colombia. Sostiene luego que esta fé bastante divulgada durante la fase pre-animista hubiera inducido à los hombres, en parte a que adoptaran diversos modos de la momificación de los muertos

(1) Excepcionss de los últimos tiempos son: Gerdt Kutscher, Iconographic studies as an ald in the reconstruction of Early Chimú civillzation. Transactions or the studies as an my of Sciences, vol. 12, New York 1950, p. $194-203$ (Estudios inconofráficos para con-
tribuir a una reconstrucción de la Clvilización Proto-Chimú. Memoria Clencias de New York.............) -del mismo: Chimú eine altindianisch de la Academia de mú, una cultura alta de los indios antlguos), Berlin 1950._Karin Hissink, Gedanken su einem Nazca-Gefass (Pensamiento estilo Nazca), El Mexico antiguo. Tomo VII. Mexico (ensamientos alrededor de un huaco 
como asimismo diferentes métodos para conservar la forma corpórea, p. ej. rellenando la piel humana o modelando las facciones en cera etc., y en parte hubiera dado el impulso a que produjeran plásticas de sustitución tales como mascarillas de barro y oro, figuras de oro y barro, cuya función era la de representar al muerto. (2) Con respecto a las tribus del valle de Cauca, Eckert dice literalmente: "El hecho de equiparar el retrato a la forma original, indujo probablemente a las tribus del valle de Cauca a que dieran a los muertos en la tumba plásticas antropomorfas". Para Eckert no es inverosímil que, así como en el caso de la cerámica antropomorfa del Proto-Chimú, también en el valle de Cauca se haya equiparado el retrato a la forma corporal. Dice que también en las reproducciones antropomorfas de los orfebres del valle Cauca se manifestaba la "ambición de propiedad en el retrato". Como prueba de lo dicho alega la atención que se pone en diferenciar los sexos, el tatuaje y la pintura respectivamente, y el adorno; "que bajo estas figuras", así argumenta, "hemos de ver retratos de difuntos, lo demuestran los ojos cerrados, ya que éstos muy bien caracterizan la ausencia de vida". (3)

Sin tener la intención o siquiera la disposición de comentar aquí las investigaciones amplias de Eckert y su interpertación de las costumbres del enterramiento en el valle Cauca, quisiera yo ocuparme de las ofrendas funerarias de una región que me es mucha más familiar y de la cual Eckert parte en sus argumentaciones, quiero, a saber: dedicar a las plásticas antropomorfas de los mochicas, de aquel pueblo de civilización antigua habitaba los oasis de los ríos norteños del Perú, "valles del Nilo en miniatura". como los llamó en una ocasión W. D. Strong.

Eckert considera como "Orientador" un artículo acerca de la cerómica antropomorfa dedos mochicás, quie procedé de la pluma de Angel Tuya, cuya desaparición demasiado temprana lamentamos; para mejor inteligibilidad de sus propias interpretaciones, Eckert cita la siguiente frase del etnólogo español: "'os huaco-retratos, reproduciendo meramente la cabeza humana con una perfección que alcanza a veces un grado extraordinario, deberán haber servido a un fin mágico, el que corresponde al de la momificación: tal como en la momificación, lo que se anhela es evitar la descomposición del cuerpo, su destrucción y con ella la muerte definitiva del cadáver vivo, precisamente así los dichos

(2) Georg Eckert, Totenkult und Lebensglaube Im Caucatal (El culto de los muertos y creencla sobre la vida en el valle de Cauca), Branuschwelg 1948. Eckert, no 1gnora que sin embargo. poder ver un " pueblos de orlentación animistica y no animistlca; cree, cla del "cadaver vivo" espe "predominlo de ideas no-animísticas" y sobre todo la creenmuy primitiva. Comprende entrente en las zonas de, culturas altas de la fase primitiva y el Reino Menfita, el Reino entre ellas las primeras fases de las culturas altas del oriente, y en la Edad de Bronce, como los Súmesos, las clvilizaciones de la Egelda en el Neolitico de América, entre ellas la de asimlsmo las diferentes clvilizaciones desarrolladas ("relf")

(3) Ibldem p. 22 s, 
huaco-retratos habían de garantizarle al muerto que él continuará viviendo, por más que el cuerpo pase al estado de putrefacción". (4).

Pero se comprende que la plástica antropomorfa de los mochicas en su complejidad, encierra paru el espectador moderno misterios que no se dejan aclarar sin más. Refiriéndome a las exposiciones de Tuya, formularé en lo siguiente algunas objeciones a base de mis propias opiniones y reflexiones, y voy a proponer, con toda reserva, esta y aquella tentativa de una interpretación.

Tuy subdivide someramente las reproducciones humanas de los mochicas en cuatro grupos: 1).--El primer grupo abarca "tipos de hombres "normales, cuya representación nos sugiere que sean retratos". Su función de ser ofrendas funerarias, interpreta Tuya en el sentido de que hubieran tenido una finalidad correspondiente a la de la momificáción, a saber: de preservar el "cadáver vivo", sujeto a la putrefacción, de una muerte definitiva. Tal interpretación se basa en el supuesto -que no es seguro en modo alguno- de que las figuras y cabezas cerámicas representen efectivamente retratos del muerto, en cuya tumba fueron colocados. (5).

Al reflexionar sobre esto, un argumento que no hay que traer de muy lejos, demuestra en forma irreprochable, que dicho supuesto no puede ser acertado. Como es sabido, los mochicas modelaron sus figuras de barro mediante moldes de barro, que consistían en dos mitades del negativo de la plástica por hacer. Pues bien, tales formas negativas conducen evidentemente a una labricación en masa, procedimiento que en sí constituye una contradicción al profundo sentido ritual, con el cual sin duda tenían que ver estas esculturas de barro. Ahora es un hecho, que un mismo retrato aparece de vez en cuando en varias tumbas. Por lo tanto, se desvirtúa con teda avidenciáa la interpretación de tratarse de un retrato del individuo mismo que está sepultado.

Dediquemos por lo pronto nuestra atención a las plásticas de barro de los mochicas, que se asemejan a retratos, ocupémonos, a saber: de los así llamados cabeza-retratos; es de suponer que ellos pertenecen a la segunda mitad del primer milenario de J. C. Allcanzan una perfección tal de su realismo, reproductivo, que en vano buscaríamos algo parecido en ningún período, en ninguna zona de toda América antigua. El nombre "cabeza-retratos" suele aplicarse también a cierta clase de cabecitas shiquitas de barro de la civilización Teotihuacan en México, en las cuales no es justificado, como recalca con mucha razón Linné ( 6$)$. ,

(4) Angel de Tuya: Die anthropomorphe Proto-Chlcmú-Keramic, zeltschrlft für Ethnologle; 67. Jahrgang, S. 265-69, Berlin 1936 (La cerámica antropomoria del Proto-Chimu,
Revista de Etnologfa, Año 67......)

(5) Ver Tuya, cap. cit. p. 267. - Eckert, cap. cit. p. 24.

(6) Ver Slgvald Linné: Mexican Highland Cultures (Las

Mexlco), Stockholm 1942. P. 59.- Es poslble, slnembargo, culturas de las tlerras altas de de barro de la Cultura Teotlhuacan, las que no fueron que nlgunas de estas cabecitas 
Es Ubbelohde-Doering, verdadero conocedor de las obras plásticas de antigüedad peruana, quien, con mucha intuición, determinó el significado de los cabeza-retratos creados por los mochicas: "Testimonio de la fé que se tuvo en el poder de los muertos, son también los cabezaretratos, procedentes de los cementerios de la Civilización Moche, sobre todo del valle de Chicama, los que llegaron a tener fama. Aunque fueran sacados de tumbas, sin embargo no es de suponer que alguna vez hayon representado al individuo sepultado en calidad de su retrato. Muchas reproducciones de estas cabezas existen en varias ediciones . . . Deben de ser retratos de eminentes personajes poderosos de la época primitiva, retratos de príncipes, jetes o sacerdotes. Si ocupa un nivel más alto, haciéndose más poderoso, cun el difunto que pertenecía a la masa del pueblo, cuánto más debe haberse encumbrado con la muerte, alcanzando una autoridad casi divina, un miembro de la aristocracia o el soberano mismo. La potencia mágica de un hombre, era concentrada en su cabeza. Ahora bien, la cabeza de alguien semejante a los dioses, pudo convertirse en una fuerza inapreciable a disposición del muerto a quien se le agregó una tal cabeza mágica en la tumba. De manera que se volvía a modelar una y varias yeces la misma cabeza, para sacar de la plenitud del poder mágico, propio al noble difunto, un poco también para otros que eran de una condición inferior". (7).

Lo que acabamos de leer en la última frase acerca de repetidas reproducciones de la misma cabeza, vemos corroborado por el testimonio de Rafael Larco Hoyle. Según él se encontró un retrato de la misma cara en tres diferentes valles, separados los unos de los otros por fajas más o menos anchas de desierto, a saber: En los valles de Chicama, Virú y Santa. Larco "cita aun uffos casos en los que había repetición de retratos de personajes idénticos, hallándose éstos en tumbas situadas en diferentes valles. De igual manera supone Strong acerca de un huaco-retrato al cual encontró en la tumba de una mujer en el valle de Virú, que haya sido confeccionado mediante el mismo molde que sirvió para otros huacos-retratos conocidos por él y los que pertenecieron al valle de Chicama, teniendo todos estos en común el rostro y el tocado. Es digno de verse que en aquel retrato sacado de la tumba de una joven mujer, se trata de la imagen de un guerrero o de un noble, que tiene orejeras y lleva un halcón en su tocado. De modo que no se puede hablar de un retrato de la mujer sepultada. Era relativamente fá-

barro sino hechas a mano libre, se trate de un verdadero arte del retrato, y a veces hasta de obras insignes. "Aqui los seres humanos hacen su aparición por medio del enjambre de dioses, demonios y de representaciones máglcas o simbólicas". - Linné, cap. clt.

(7) Heinrich Ubbelohde-Doering: Altperuanische, Kunst (Arte del antiguo Perú), Berlín 1936, p. 4. 
cil determinar edad y sexo en estos difuntos, puesto que una mascarilla de cobre les cubre la cara, conservando bien cráneo y rostro ( 8 ).

Y en efecto, no hacía falta ningún sustituto de "cadaver vivo" a base de retratos puesto que en acuel clima de desierto hasta cadáveres que no fueron sometidos a un proceso de momificación artificial, se conservan bien durante algunos siglos cuando menos. No son, pues, casos excepcionales, que se encuentran cadáveres de los siglos desde antes de la Conquista, los cuales, sin haber sido embalsamados, tienen facciones claramente reconocibles y el pelo intacto, después de ser enterrados por lo menos cuatrocientos años antes.

Lo que se ha dicho acerca de los cabeza-retratos, es válido también para las figuras de cuerpo entero. Parece que también bajo esta forma los mismos individuos fueron reiratados reiteradas veces, o más bien que el mismo retrato se ha reproducido a menudo (9). Verdad es que hoy tales figuras, cuyas variaciones fisonómicas son aparentemente mucho más reducidas; en estos casos nos inclinamos a pensar en la mayor estandarización de un determinado ideal de belleza (10). Larco toma las representaciones de un trombre barbudo que se encontraron en varios lugares de la zona Mochica, por retratos de un mismo individuo, siendo así que precisamente en este caso la opinión se inclina generalmente en favor de la repetición de un determinado tipo, - a no ser que se trate aquí tal vez de la representación de un determinado personaje mitológico (11).

De paso queremos anotar, que en los respectivos cabeza-retratos saltan a la vista marcadas diferencias en cuanto a raza y fisonomía, algo que apenas se observa en las figuras estandarizadas. En unos cabezaretratos hay más o menos manifiestos rasgos mongoloideos, frente a las características más raras en otros que casi podrián calificarse de negroides, habiendo, a más de eso, retratos de algunos individuos que recuerdan directamente caras europeas. Luego existen otros tipos que encontramos hoy de vez en cuando entre los indios habitantes de la región alta cuzqueña (12). Por otra parte no creo yo, que no necesariamente

(8) Rafael Larco Hoyle: Los Mochicas. Lima, 1936. Tom. II, p. 132 s. Figuras 192, 193. 194. Es verdad que los ejemplos de Larco no enseñan claramente, si siempre se han modelado las mismas cabezas, usándose el mismo molde. De todos modos varia a menudo la pintura y a veces aparecen aún diferentes agregados plásticos en el tocado. Pero al compararse colecciones más grandes, resultará de un modo irrefutable, que si, existe un número considerable de huaco-retratos procedentes de moldes Idénticos. - william Duncan strong: Flnding the tomb of a warrlorgod (Descubrimiento de la tumba de un diosguerrero) National Geographic Magazlne. Washington 1947, p. 476.

(9) Ver Larco H. cap.. cit. p. 23 y fig. 136.- A. Kroeber: The Uhle pottery collection from Moche (La colección de alfarería Moche de Uhle), Berkeley 1925. P1. 53d, 1 .

(10) Larco H. cap. cit. p. 141. fig. 195, 196.

(11) Ver Larco p. 23 y fig. 136. - Koeber cap. cit. Pl. 53d, 1

(12) Ver $\mathrm{H}$. Ubbelonde-Doering: Auf deu Koalgstrassen der Inka. Reisenund Forschungen
Perú. (En los caminos reales de los Incas. Vlajes y exploraciones In Perú. (En los caminos reales de los Incas. Viajes y exploraciones en el Perú), Berlın
1941 Tab. 137, 139, 147,354, 360. 
hayan sido siempre príncipes, sacerdotes $\mathrm{u}$ otras personalidades de alto rango, los que hallamos retratados.

2.-El segundo grupo de las plásticas cerámicas, citado por Tuya, él lo explica simplemente a raíz del objeto que persiguen, como mágia por analogía. Trátase de "motivos de la vida fisiológica normal". Los sobrevivientes, que ponen en la tumba de los difuntos imágenes de durmientes, de mascadores de cocct, de parturientas y preñadas querían -esta es la idea de Tuya- hacerles participar en su estado de muertos, de aquellos asuntos que les eran familiares durante el curso de su vide (13).

Antes de declararnos conformes con tal explicación, habría de aveguarse si por ejemplo: tales imágenes de parturientas o de encintas se ucontraron en realidad siempre en tumbas de mujeres, es decir si las rencionadas reproducciones habrían llegado siempre a la tumba corespondiente. A más de esto cabe preguntarse: ¿de qué provecho setían representaciones de prisioneros para un muerto? ¿qué sentido tieien las frecuentes escenas pictográficas de batallas y luchas? ¿qué senido por fin, revelan las frecuentes escenas pictográficas de batallas y luchas? Vemos surgir un complejo de mil preguntas que no tienen posibilidad de hallar respuesta adecuada. ¿Qué tiene que ver por ejemplo con el inquilino de una tumba cquel borracho que está lleno de dulce chicha de maíz, al cual acompañan sus amigos a casa? ¿será posible que también el difunto era un borracho mientras estaba entre los vivos? (14).

Es un hecho apenas creíble, que para la región mochica - de la que tantos especímenes favoritos llegaron de las manos de buscadores de tesoros y traficantes a coleccionescprivadas ynpúblicas de más de medio mundo- desgraciadamente no existieran casi ningunas publicaciones de tumbas enteras (15). Sólo investigaciones críticas de complejos íntegros de tumbas y cotejos suficientemente extensos de las ofrendas funerarias, procedentes de la mayor cantidad posible de tumbas particulares, podrían facilitar quizá una respuesta más o menos satisfactoría a la pregunta por la finalidad y el sentido de los accesorios sepulcrales.

Por más que se puede partir de la costumbre muy divulgada de que el muerto solía recibir alimentos y bebidas para satisfacción de necesidades físicas, sin embargo con esto no se ve todavía garantizado ese status de una creencia "pre-animística", ya que alimento y bebida tienen muchas veces sólo la función de un viático para el camino hacia el

(13) Tuya, cap. clt. p. 267.

(14) Gerdt Kutscher, Chimú, Berlín 1950, Tab. 41.

(15) Aqui se destaca como excepción meritoria el articulo cltado bajo (6) de W. D. Strong. Fialta, hasta donde yo sepa, una publicación cientiflca del material tratado por él. - Pueden esperarse de él como de la publicación de Ubbelohde-Doering sobre exploraclones de tumbas en Pacatnamú cerca de Pacasmayo, datos vallosos. 
otro mundo.- A más de esto cabe preguntar, si las frecuentes representaciones escultóricas y pictográficas de los antiguos mochicas, que muestran muertos y esqueletos bailando al son de la flauta, no contradicen a las ideas del "cadaver vivo", de acuerdo con la concepción de Eckert y de Tuya.

3).-Como tercer grupo de Iepresentaciones antropomorfas de los alfareros mochicas cuenta Tuya las reproducciones de fenómenos patológicos, cuyas señales de deforinidad horripilantes, sobre todo en las caras, no deja nada que desear en cuanto al realismo del detalle. Tales ofrendas destinadas a los muertos, porsupuesto, no pueden explicarse con el recurso de simple mágia por analogía realizable en favor del sepultado. Tuya, al contrario, en caso que el difunto fuere expuesto una vez a tales enfermedades. Reproducciones de esta clase, según él, hubieran tenido la función de atraer sobre sí el mal y de ejercer un efecto curativo (16).

No sería, en verdad, más natural -ateniéndonos siempre a la premisa del "cadaver vivo" - suponer, que el difunto padecía en vida de tal enfermedad y que se le quería proporcionar por lo menos en la tumba su remedio? O no podría ser también que los vivos necesitaban de los milagrosos y poderosos muertos, a los que se les atribuía fuerzas curativas y los que se suponían en contacto con el mundo de los dioses? ¿no se les imploró en calidad de salvadores, a manera de los santos católicos, a los que se refugian los fieles en los lugares de peregrinación rezándoles y ofreciéndoles modelos de cera, para que curaren los miembros enfermos? - un iconcepto parecido sostiene Ubbelohde- Doering al considerar como un "mundo de símbolos" a aquel mundo de imágenes que representan las fofrendas funerarias, viendo objetos confeccionados casi siempre exclusivamente para el muerto; ellas constituyen símbolos por medio de los cuales, los deseos, las oraciones, preocupaciones y la desesperación de toda una humanidad extinguida ha tomado cuerpo, significando una presencia mágica llena de vida" (17).

4).- Mayores dificultades frente a una interpretación de su significado opone tal vez la cerámica antropomorfa que Tuya enumera en el cuarto y último grupo, tratánciose de motivos de la vida sexual. Tuya sostiene y su aseveración es fácil de desvirtuar -que entre las reproducciones de acciones sexuales de toda índole concebible, prevalecían los oasis de homosexualidad. En calidad de argumento respecto de la inversión sexual difundida regionalmente, él cita lugares de Cieza de León y de Oviedo y Valdés, lugares que, en realidad, no se refieren a los mochicas: opina que la creencia de la continuación material de la vida después de la muerte había inducido a los sobrevivien-

(16) Tuya, cap. cit. p. 268.

(17) Ver U. -Doering: Altperuaniscche Kunst (Alte del antiguo Perú), p. 1 ss, 
tes a que proporcionaran a los difuntos, aun después de la muerte, los placeres de los cuales habían disfrutado en la vida. Esto se quería efectuar mediante ofrendas funerarias de la índole mencionada, "cuya verdadera finalidad parece haber consistido en el ejercicio de una mágia sexual" (18). Estando de acuerdo con respecto al último punto, añadimos, que el significado de tan extrañas ofrendas es probablemente de más difíciles alcances y que la mágia anhelada era pensada en algún sentido figurativo.

Surge nuevamente la pregunta: ¿a qué clase de difuntos se dedicaron representaciones, de las más variadas acciones sexuales?' Y̌o conozco un caso concreto -desgraciadamente el único- en el cuai se manifiesta una referencia a tales ofrendas; es un caso que cuenta Larco Hoyle, siendo el difunto un riño (19). Dicho caso concreto no serviría entonces de ninguna manera a confirmar las interpretaciones de Tuya. Por lo mismo deben averiguarse otras intenciones de los mochicas.

Larco Hoyle quiere ver en algunos especímenes de contenido sexual intenciones humorísticas mientras que en otros se haya tratado de alguna moraleja castigadora. Ciertamente tales explicaciones se concibieron a raíz de puntos de vista demásiado modernos $y$, por tanto, han de descartarse de antemano. Más recomendable será tal vez pensar en fines e intenciones rituales, comenzando con representaciones fálicas, las que permitirían quizá conclusiones en dirección hacia una mágia de fecundidad. Más patente es el contenido religioso en las representaciones de dioses o demonios en el acto de la copulación. Dispone de reproducciones de esta clase también la colección del Museo Monacense de Etnología (Müchner Museum für Volkerkunde). Trátase, es verdad, en parle de obras procedentes del Chimú-Posterior, el cual acogió sólo parcialmente la herencia de la antigua civilización mochica.

Tracl. G. Ibscher R.

(18) Tuya, cap. c1t. p. 269.

(19) Rafael Larco Hoyle: A cultura sequence of the North Coast of Perú. (Una serle de culturas en la costa Norte del Perú) Hisandbook of South Amerlcan Indlans (Manual sobre los indíos de América del sur). vol. 2 p. 175. 